\title{
Article \\ Behavioral and Mental Responses towards the COVID-19 Pandemic among Chinese Older Adults: A Cross-Sectional Study
}

\author{
Wei Liang ${ }^{1,2} \mathbb{D}$, Yanping Duan ${ }^{1,2,3, *}$, Min Yang ${ }^{2}$, Borui Shang ${ }^{4}$, Chun $\mathrm{Hu}^{5}$, Yanping Wang ${ }^{2}$ and \\ Julien Steven Baker 1,2 (iD
}

check for updates

Citation: Liang, Wei, Yanping Duan, Min Yang, Borui Shang, Chun Hu, Yanping Wang, and Julien Steven Baker. 2021. Behavioral and Mental Responses towards the COVID-19 Pandemic among Chinese Older Adults: A Cross-Sectional Study. Journal of Risk and Financial Management 14: 568. https:// doi.org/10.3390/jrfm14120568

Academic Editor: Thanasis Stengos

Received: 1 October 2021

Accepted: 16 November 2021

Published: 24 November 2021

Publisher's Note: MDPI stays neutral with regard to jurisdictional claims in published maps and institutional affiliations.

Copyright: (C) 2021 by the authors Licensee MDPI, Basel, Switzerland. This article is an open access article distributed under the terms and conditions of the Creative Commons Attribution (CC BY) license (https:/ / creativecommons.org/licenses/by/ $4.0 /)$.
1 Center for Health and Exercise Science Research, Hong Kong Baptist University, Hong Kong 999077, China; wliang1020@hkbu.edu.hk (W.L.); jsbaker@hkbu.edu.hk (J.S.B.)

2 Department of Sport, Physical Education and Health, Hong Kong Baptist University, Hong Kong 999077, China; myanhkbu@gmail.com (M.Y.); yanniswyp@163.com (Y.W.)

3 College of Health Sciences, Wuhan Institute of Physical Education, Wuhan 430000, China

4 Department of Kinesiology, Hebei Institute of Physical Education, Shijiazhuang 050000, China; boruishang@hepec.edu.cn

5 Student Mental Health Education Center, Northwestern Polytechnical University, Xi'an 710000, China; huchun52@163.com

* Correspondence: duanyp@hkbu.edu.hk

\begin{abstract}
The novel COVID-19 pandemic spread quickly and continuously influenced global societies. As a vulnerable population that accounted for the highest percentage of deaths from the pandemic, older adults have experienced huge life-altering challenges and increased risks of mental problems during the pandemic. Empirical evidence is needed to develop effective strategies to promote preventive measures and mitigate the adverse psychological impacts of the COVID-19 pandemic. This study aimed to investigate the behavioral responses (i.e., preventive behaviors, physical activity, fruit and vegetable consumption) and mental responses (i.e., depression and loneliness) towards the COVID-19 pandemic among Chinese older adults. A further aim was to identify the associations among demographics, behavioral responses, and mental responses. Using a convenience sampling approach, 516 older adults were randomly recruited from five cities of Hubei province in China. Results of the cross-sectional survey showed that $11.7 \%$ of participants did not adhere to the WHO recommended preventive measures, while $37.6 \%$ and $8.3 \%$ of participants decreased physical activity and fruit-vegetable consumption respectively. For mental responses, 30.8\% and $69.2 \%$ of participants indicated significantly depressive symptoms and severe loneliness, respectively. Participants' behavioral and mental responses differed significantly in several demographics, such as age group, living situation, marital status, education levels, household income, medical conditions, and perceived health status. Demographic correlates and behavioral responses could significantly predicate the mental response with small-to-moderate effect sizes. This is the first study to investigate the characteristics of behavioral and mental responses of Chinese older adults during the COVID-19 pandemic. Research findings may give new insights into future developments of effective interventions and policies to promote health among older adults in the fight against the pandemic.
\end{abstract}

Keywords: COVID-19; preventive behaviors; physical activity (PA); fruit and vegetable consumption (FVC); depression; loneliness; older adults; China; behavioral response; mental response

\section{Introduction}

The novel coronavirus disease (COVID-19) has continuously influenced global societies, causing over 219 million confirmed cases and 4.55 million deaths as reported on 25 September 2021 by the World Health Organization (WHO 2021a). In China, there have been more than 96,000 confirmed cases and over 4600 fatality cases to date (National Health Commission of China 2021; CSSE 2021). As a vulnerable group, older adults have accounted for the highest proportion of deaths from COVID-19 (approximately 75\%) 
(Shahid et al. 2020; World Health Organization 2020). During the COVID-19 pandemic, healthy ageing advocacy is being confronted with a great challenge.

To reduce the human-to-human transmission of the coronavirus, many countries enacted the emergent lockdown policy and implemented strict control measures for the pandemic (Cheng et al. 2020; Hu et al. 2021). For example, in China, the government of Hubei Wuhan imposed an urgent lockdown on 23 January 2020, with travel restrictions. Despite the positive effects in preventing the spread of the pandemic, these governmental actions have led to great life-altering challenges for individuals especially for older adults, e.g., the routinization of practicing preventive behaviors (PB) in daily life, and huge changes in physical activity (PA), and dietary behavior, e.g., fruit-and-vegetable consumption (FVC) (Li et al. 2020; Dwyer et al. 2020; Weaver et al. 2021).

In addition to the lifestyle changes, older adults have a high risk of psychological distress during the pandemic. Compared with other age groups, older adults are more likely to experience fear of becoming ill or dying during the pandemic, which may be accompanied by feelings of helplessness and stigma (Khan et al. 2020; Vahia et al. 2020). These feelings can lead to a series of negative mental responses and problems, such as loneliness and depression, consequently imposing adverse influences on the overall health and well-being of older adults (Khan et al. 2020; Vahia et al. 2020; Singh and Singh 2020). This will also impose a series of negative impacts on diverse aspects of society, such as burdening the medical systems and affecting the success in the labor market (Codagnone et al. 2020; Usher et al. 2020). Older adults' behavioral and mental responses during the pandemic not only provides useful information for health risk communication and pandemic prevention but also contributes to achieving the advocacy of healthy ageing.

\section{Literature Review}

Individuals' behavioral responses during the pandemic usually include three major aspects: PB adherence, PA change, and dietary change (e.g., FVC) (Weaver et al. 2021; Puspitasari et al. 2020; Balkhi et al. 2020). Individual precautionary actions, such as hand washing, facemask wearing, and physical distancing, which are recommended by the WHO and other health authority organizations (World Health Organization 2020; Probst et al. 2020), have become individual's daily routines. An overwhelming amount of evidence has demonstrated that adhering to these three PB could effectively inhibit the transmission of COVID-19 and reduce the probability of infection (Probst et al. 2020). Several studies have examined the practice of $\mathrm{PB}$ among populations from diverse countries and regions (Arora and Grey 2020; Ye et al. 2020). For example, a review study summarized the knowledge, attitude, and practice of PB during the pandemic among healthcare workers, medical students, and populations in the US, the UK, Italy, Jordan, and China in the initial stage of the pandemic (Arora and Grey 2020). Some empirical studies also investigated the PB adherence among adults and internet users in China (Li and Liu 2020; Ye et al. 2020). However, there is limited evidence particularly targeting the characteristics of $\mathrm{PB}$ adherence among older adults, especially in China. For PA and FVC, a recent review summarized the results of 41 studies finding that most of the evidence identified a decrease in PA levels during the pandemic, whereas only one study targeted community-dwelling older adults (Caputo and Reichert 2020). Several studies have investigated the FVC behavior among children and adults, while evidence for Chinese older adults is still limited (López-Bueno et al. 2020; Litton and Beavers 2020).

Behavioral responses have been evident to impose considerable influences on individuals' mental health outcomes/responses. For example, recent studies have indicated an inverse association of adhering to $\mathrm{PB}$ with mental distress among adolescents and adults (Wang et al. 2020; Cunningham et al. 2020; Gehlich et al. 2019). This may generate urgently needed insights into the mitigation of negative mental impacts of the pandemic. Nevertheless, there are few studies examining the impact of adhering to PB on mental health outcomes among older adults. For PA and FVC, as a common healthy lifestyle pattern, they also play an irreplaceable role in the battle with the COVID-19 pandemic, as through 
engaging in regular PA and consuming sufficient FVC individuals could enhance their cardiorespiratory fitness and immune function, as a result reducing the risk of death from viral infection (Amatriain-Fernández et al. 2020; Yahia et al. 2017). However, self-isolation and restrictions during the pandemic dramatically reduced the opportunities for individuals to be physical active and increase the possibilities of unhealthy diets (e.g., insufficient FVC). These unfavorable behavioral changes may lead to adverse mental consequences, e.g., worsening loneliness and depression, among older adults. Investigating the impact of such behavioral responses towards the pandemic in older adults should be prioritized. To the best of our knowledge, few studies have examined the relationship between all three behavioral responses (PB adherence, $\mathrm{PA}$, and $\mathrm{FVC}$ ) and mental responses (loneliness and depression) among older adults during the COVID-19 pandemic.

Given the lack of empirical research in China, the current study aimed to (1) investigate the demographic characteristics of behavioral (i.e., PB, PA, and FVC) and mental responses (i.e., loneliness and depressive symptoms) among Chinese older adults, and (2) examine the interrelationships between demographics, behavioral responses, and mental responses among Chinese older adults.

\section{Materials and Methods}

\subsection{Study Design and Participants}

To address the above objectives, this study used a cross-sectional design, and the data was collected from 15 June to 10 July 2020 (the lockdown had been withdrawn for over two months) with a convenience sampling approach. The sample size was calculated using $G^{*}$ Power 3.1 software. For achieving a medium effect size (Cohen's $f^{2}=0.15$ ) on the prediction of demographics and behavioral correlates in mental responses based on previous studies with older adults (Pinquart 2001), with an alpha of 0.05, a statistical power of $80 \%$, and a response rate of $60 \%$, a total of 205 participants were required. As shown in Figure 1, we contacted 727 participants and received an $83.8 \%$ response rate. Finally, 516 participants were included in data analysis. The eligible criteria included (1) older adults who are $\geq 60$ years old; (2) not having been infected with COVID-19; (3) not having any cognitive disorders or impairments; (4) having access to a mobile phone or laptop; and (5) having sufficient reading or listening skills in Mandarin. For participants who have difficulties in using mobile phones or laptops, their family members or friends were invited to assist them in completing the online survey. The study was implemented and reported following the guidelines of the STROBE checklist.

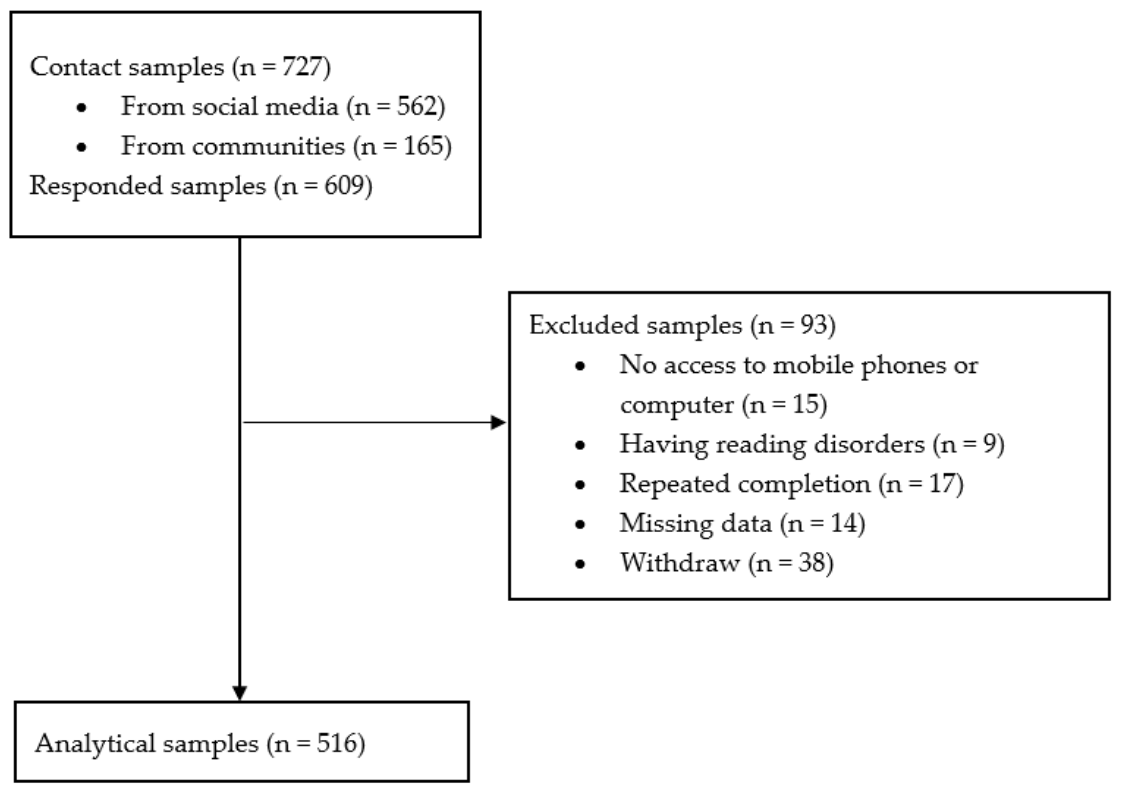

Figure 1. Flow diagram of participant recruitment. 


\subsection{Procedure}

The questionnaire survey was administered using an online survey platform, namely SOJUMP (Changsha Ranxing Information Technology Co., Ltd., Changsha, China). The recruitment information was delivered by different social media channels, such as WeChat, Weibo, and QQ which are popular in China. In addition to the social media channels, researchers contacted the administration staff in several universities and neighborhood communities to facilitate recruitment to retired colleagues.

The duration of completing the online survey was about 15-20 minutes. To increase the engagement of participation, each participant who completed the questionnaires was provided with $30 \mathrm{RMB}$ incentive by electronic transfer via WeChat or Alipay or by prepaid telephone recharge. All participants were asked to sign an informed consent form on the first page of the survey website prior to filling in the questionnaires. Ethical approval for the study was obtained from the Research Ethics Committee of Hong Kong Baptist University (REC/19-20/0490).

\subsection{Measures}

\subsubsection{Behavioral Responses}

- $\quad$ Preventive behaviors (PB): the adherence to the $\mathrm{PB}$ was measured by six items covering the three major $\mathrm{PB}$ as recommended by the $\mathrm{WHO}$, including hand washing, facemask wearing, and physical distancing (WHO 2021b). Each behavior was assessed by two items. For example, the items for hand washing were asked with the stem of "during the previous week, I adhered to washing my hands with soap and water or alcohol-based hand rub (for at least $20 \mathrm{~s}$, on all surfaces of the hands) ..." " followed by two situations including "(a) in a daily life situation, e.g., before eating, and (b) in a disease-related situation, e.g., after caring for the sick." All responses were indicated on a 4-point Likert scale ranging from " $1=$ strongly disagree" to " $4=$ strongly agree" (Liang et al. 2021). Participants who indicated "agree/strongly agree" for all six items were coded as " $1=$ adhering to $P \mathrm{~PB}^{\text {", }}$ otherwise as " $0=$ non-adhering to $\mathrm{PB}$ ".

- Physical activity (PA) and fruit-vegetable consumption (FVC): each behavior response was measured by one item. Participants were asked about their changes in weekly amount of PA and daily portion of FVC since the outbreak of the COVID-19 pandemic. Responses included " $0=$ less" and " $1=$ same or more".

\subsubsection{Mental Responses}

- Depression: the 10-item Chinese version of the Epidemiologic Studies Short Depression Scale (CESD-10) was used to measure the depressive symptoms (Rankin et al. 1993). The questions were asked with the stem: "In the past week, how often I feel...", followed by 10 items such as "I was bothered by things that usually don't bother me". The responses were indicated on a 4-point Likert scale, ranging from " $0=$ rarely (less than 1 day)" to " 3 = for most of the time (5-7 days)" (Cronbach's alpha $=0.82)$ (Rankin et al. 1993; Liang et al. 2019). The total score of the 10 items was calculated, where the score of $0-9$ was coded as " $0=$ no significant depressive symptoms", and $\geq 10$ was coded as " 1 = significant depressive symptoms" (Andresen et al. 1994).

- Loneliness: the 6-item Chinese version of the De Jong Grieveld Loneliness Scale was used to measure loneliness (Leung et al. 2008). The scale consisted of two dimensions (social lonely and emotional lonely), with three items for each dimension. Participants were asked with the stem "Please see if the statements are describing your situations or feelings now ..." " followed by six items, such as "I experience a general sense of emptiness" (emotional) and "There are plenty of people I can rely on when I have problems" (social) (Cronbach's alpha $=0.76$ ) (Leung et al. 2008). The total score of the 6 items was calculated, where the score of $0-3$ was coded as " $0=$ light loneliness" and $\geq 4$ was coded as " 1 = severe loneliness" (De Jong Gierveld and Van Tilburg 1999). 


\subsubsection{Demographics}

Demographic information included age, gender, living situation, marital status, educational level, occupational status, household income, perceived health status, and medical condition.

\subsection{Statistical Analysis}

Data analyses were conducted using the IBM SPSS 26.0 (Armonk, NY, USA). Mean values, standard deviation (SD), and percentage (\%) were calculated for descriptive analyses. The characteristics of behavioral and mental responses were examined using Chi-square tests. Single level and multi-level logistic regression models were used to explore the association among demographics, behavioral responses, and mental responses. The statistical significance was set at 0.05 (two-tailed). The effect sizes (Cohen's $f^{2}$ ) of association in the regression models were calculated using the formula " $f^{2}=R^{2 /}\left(1-R^{2}\right)$ ", with $0.02,0.15$, and 0.35 indicating a small, medium, and large effect, respectively (Selya et al. 2012; Duan et al. 2021).

\section{Results}

\subsection{Characteristics of the Study Sample}

A total of 516 eligible participants ( $57.9 \%$ females) were included in data analysis, ranging in age from 60 to 90 years old (Mean age $=67.6 \pm 6.6 \mathrm{yrs}$.). Over $90 \%$ of participants lived with others (e.g., spouse or children) and more than $80 \%$ of participants were married. In total, $44.8 \%$ of participants received middle or high school education, while the percentage of participants receiving college or above education was $46.5 \%$. Most participants were pensioners or retired $(92.6 \%)$, and over half of participants reported an average level of household income (57.9\%). For the medical condition, 50.8\% of participants had a history of chronic diseases. More than half of participants perceived their health status as good $(52.7 \%)$. Details can be found in Table 1 .

Table 1. Characteristics of the study sample, behavioral responses, and mental responses $(n=516)$.

\begin{tabular}{|c|c|c|c|c|c|}
\hline & PB & PA & FVC & Depression & Loneliness \\
\hline & Non-Adherence: $n(\%)$ & Decreased: $n(\%)$ & Decreased: $n(\%)$ & Yes: $n(\%)$ & High: $n(\%)$ \\
\hline \multicolumn{6}{|l|}{ Total $(n=516)$} \\
\hline \multicolumn{6}{|l|}{ Age $(n, \%)$} \\
\hline 60-69 yrs. $(354,68.60 \%)$ & $36(10.2 \%)$ & $125(35.3 \%)$ & $23(6.5 \%) *$ & $105(29.7 \%)$ & $233(65.8 \%)$ \\
\hline $70-79$ yrs. $(128,24.80 \%)$ & $128(11.7 \%)$ & $52(40.6 \%)$ & $13(10.2 \%) *$ & $42(32.8 \%)$ & $76(59.4 \%)$ \\
\hline$\geq 80$ yrs. $(34,6.60 \%)$ & $34(11.8 \%)$ & $17(50.0 \%)$ & $7(20.6 \%) *$ & $12(35.3 \%)$ & $18(52.9 \%)$ \\
\hline \multicolumn{6}{|l|}{ Gender $(n, \%)$} \\
\hline Male $(217,42.10 \%)$ & $26(12.0 \%)$ & $77(35.5 \%)$ & $19(8.8 \%)$ & $69(31.8 \%)$ & $132(60.8 \%)$ \\
\hline Female $(299,57.90 \%)$ & $29(9.7 \%)$ & $171(39.1 \%)$ & $24(8.0 \%)$ & $90(30.1 \%)$ & $195(65.2 \%)$ \\
\hline \multicolumn{6}{|l|}{ Living situation $(n, \%)$} \\
\hline Alone $(48,9.30 \%)$ & $13(27.1 \%) * * *$ & $20(41.7 \%)$ & $7(14.6 \%)$ & $21(43.80 \%) *$ & $29(60.4 \%)$ \\
\hline Not alone $(468,90.70 \%)$ & $42(9.0 \%) * * *$ & $174(37.2 \%)$ & $36(7.7 \%)$ & $138(29.5 \%)^{*}$ & $298(73.7 \%)$ \\
\hline \multicolumn{6}{|l|}{ Marital status $(n, \%)$} \\
\hline Single $(14,2.70 \%)$ & $3(21.4 \%) *$ & $7(50.0 \%)$ & $1(7.1 \%)$ & $5(35.7 \%) * *$ & $10(71.4 \%)$ \\
\hline Married $(432,83.70 \%)$ & $39(9.0 \%) *$ & $154(35.6 \%)$ & $33(7.6 \%)$ & $120(27.8 \%)^{* *}$ & $275(63.7 \%)$ \\
\hline Divorced/widowed $(70,13.60 \%)$ & $13(18.6 \%) *$ & $33(41.7 \%)$ & $9(12.9 \%)$ & $34(48.6 \%)^{* *}$ & $42(60.0 \%)$ \\
\hline \multicolumn{6}{|l|}{ Educational level $(n, \%)$} \\
\hline Primary school or below $(45,8.70 \%)$ & $12(26.7 \%)^{* * *}$ & $18(40.0 \%)$ & $5(11.1 \%)$ & $21(46.7 \%) *$ & $28(62.2 \%)$ \\
\hline Middle or High school $(231,44.80 \%)$ & $29(12.6 \%)^{* * *}$ & $81(35.1 \%)$ & $21(9.1 \%)$ & $74(32.0 \%) *$ & $149(64.5 \%)$ \\
\hline College or above $(240,46.50 \%)$ & $14(5.8 \%) * * *$ & $95(39.6 \%)$ & $17(7.1 \%)$ & $64(26.7 \%)^{*}$ & $150(62.5 \%)$ \\
\hline \multicolumn{6}{|l|}{ Occupational status $(n, \%)$} \\
\hline Employed $(16,3.10 \%)$ & $3(18.8 \%)$ & $2(12.5 \%)$ & $0(0.00 \%))$ & $4(20.5 \%)$ & $11(68.8 \%)$ \\
\hline Pensioner or retired $(478,92.60 \%)$ & $47(9.8 \%)$ & $186(38.9 \%)$ & $40(8.4 \%)$ & $146(30.5 \%)$ & $303(63.4 \%)$ \\
\hline Unemployed $(22,4.30 \%)$ & $5(9.10 \%)$ & $6(27.3 \%)$ & $3(13.6 \%)$ & $9(40.9 \%)$ & $13(59.1 \%)$ \\
\hline
\end{tabular}


Table 1. Cont.

\begin{tabular}{|c|c|c|c|c|c|}
\hline & PB & PA & FVC & Depression & Loneliness \\
\hline & Non-Adherence: $n \mathbf{( \% )}$ & Decreased: $n(\%)$ & Decreased: $n$ (\%) & Yes: $n(\%)$ & High: $n(\%)$ \\
\hline \multicolumn{6}{|l|}{ Household income $(n, \%)$} \\
\hline Below average $(113,21.90 \%)$ & $21(18.6 \%)^{* *}$ & $43(38.1 \%)$ & $10(8.8 \%)$ & $48(42.5 \%) * *$ & $69(61.1 \%)$ \\
\hline Average $(299,57.90 \%)$ & $28(9.4 \%) * *$ & $108(36.1 \%)$ & $24(8.0 \%)$ & $89(29.8 \%) * *$ & $191(63.9 \%)$ \\
\hline Above average $(104,20.20 \%)$ & $6(5.8 \%) * *$ & $43(41.3 \%)$ & $9(8.7 \%)$ & $22(21.2 \%)^{* *}$ & $67(64.4 \%)$ \\
\hline \multicolumn{6}{|l|}{ Health status $(n, \%)$} \\
\hline Poor $(48,9.30 \%)$ & $6(12.5 \%)$ & $21(43.80 \%)$ & $5(10.4 \%)$ & $28(58.3 \%)^{* * *}$ & $25(52.1 \%)$ \\
\hline Satisfactory $(196,38.00 \%)$ & $24(12.20 \%)$ & $84(42.90 \%)$ & $19(9.7 \%)$ & $69(35.2 \%) * * *$ & $119(60.7 \%)$ \\
\hline Excellent $(272,52.70 \%)$ & $25(9.2 \%)$ & $89(32.7 \%)$ & $19(7.0 \%)$ & $62(22.8 \%) * * *$ & $183(67.3 \%)$ \\
\hline \multicolumn{6}{|l|}{ Medical condition $(n, \%)$} \\
\hline No $(254,49.20 \%)$ & $28(11.0 \%)$ & $83(32.7 \%) *$ & $16(6.3 \%)$ & $66(26.0 \%) *$ & $167(65.7 \%)$ \\
\hline Yes $(262,50.80 \%)$ & $27(10.3 \%)$ & $111(42.4 \%)$ * & $27(10.3 \%)$ & $93(35.5 \%) *$ & $160(61.1 \%)$ \\
\hline
\end{tabular}

Note. PB = preventive behaviors; PA = physical activity; FVC $=$ fruit and vegetable consumption; ${ }^{* * *} p<0.001,{ }^{* *} p<0.01,{ }^{*} p<0.05$.

\subsection{Characteristics of Behavioral and Mental Responses}

As shown in Table 1, $11.7 \%$ of participants did not comply with the recommended PB in response to the COVID-19 pandemic, while since the outbreak of the pandemic $37.6 \%$ and $8.3 \%$ of participants decreased their weekly amount of PA and daily portion of FVC, respectively. For mental responses, $30.8 \%$ of participants had significant depressive symptoms, while $69.2 \%$ of participants felt lonely.

Participants' behavioral responses differed significantly in a series of demographics. In particular, the compliance with PB was significantly poorer for participants who lived alone $(p=0.001)$, who were single or divorced/windowed $(p=0.023)$, received no or primary education $(p<0.001)$, and had lower household incomes $(p=0.005)$. For PA, a significantly higher percentage of participants with decreasing PA was found among those who had medical histories of chronic diseases (e.g., cardiovascular diseases, diabetes, cancer, and respiratory illness) ( $p=0.023)$, while PA change did not differ significantly in other demographics ( $p=0.054$ to 0.634 ). For FVC, participants who were in the $70-$ 79 yrs. $/ \geq 80$ yrs. age groups showed a significantly higher percentage for reducing the daily FVC compared with those in the 60-69 yrs. group $(p=0.012)$.

Regarding mental responses, the proportion of participants showing significant depressive symptoms was significantly higher among those who lived alone $(p=0.042)$, who were single or divorced/windowed $(p=0.002)$, illiterate or only received primary education $(p=0.025)$, economic disadvantaged $(p=0.003)$, perceived bad health status $(p<0.001)$, and had a medical history of chronic diseases $(p=0.019)$. For loneliness, it did not differ significantly in any demographic variables $(p=0.081$ to 0.891$)$.

\subsection{Associations of Demographic Correlates, Behavioral Responses, and Mental Responses}

As shown in Table 2, a series of binary logistic regression models were conducted to explore the association between demographics and behavioral responses among participants. For PB, results showed that $\mathrm{PB}$ non-adherence was significantly associated with living situation ( $\mathrm{OR}=0.31,95 \% \mathrm{CI}=0.12$ to $0.79, p=0.014$ ) and education levels ( $\mathrm{OR}=0.20$, $95 \% \mathrm{CI}=0.07$ to $0.59, p=0.003)$. None of the demographic variables were statistically associated with PA change ( $p=0.098$ to 0.958$)$. For FVC, participants who were in the $\geq 80$ yrs. age group were more likely to decrease the daily portion of FVC compared with those in the younger age group (60-69 yrs.) $(\mathrm{OR}=2.85,95 \% \mathrm{CI}=1.02$ to $7.95, p=0.045)$. 
Table 2. Associations of demographics and behavioral responses $(n=516)$.

\begin{tabular}{|c|c|c|c|c|c|c|}
\hline \multirow{2}{*}{ Variable } & \multicolumn{2}{|c|}{ PB Non-Adherence } & \multicolumn{2}{|c|}{ PA Decrease } & \multicolumn{2}{|c|}{ FVC Decrease } \\
\hline & OR & $95 \% \mathrm{CI}$ & OR & $95 \% \mathrm{CI}$ & OR & $95 \% \mathrm{CI}$ \\
\hline \multicolumn{7}{|l|}{ Age group (60-69 yrs. as ref.) } \\
\hline $70-79$ yrs. & 0.82 & $(0.40,1.71)$ & 1.08 & $(0.69,1.67)$ & 1.30 & $(0.62,2.75)$ \\
\hline$\geq 80$ yrs. & 0.74 & $(0.22,2.55)$ & 1.55 & $(0.73,3.31)$ & $2.85 *$ & $(1.02,7.95)$ \\
\hline \multicolumn{7}{|l|}{ Gender (male as ref.) } \\
\hline Female & 0.58 & $(0.31,1.09)$ & 1.10 & $(0.75,1.63)$ & 0.84 & $(0.43,1.64)$ \\
\hline \multicolumn{7}{|c|}{ Living situation (alone as ref.) } \\
\hline Not alone & 0.31 & $(0.12,0.79)$ & 1.19 & $(0.58,2.42)$ & 0.58 & $(0.20,1.68)$ \\
\hline \multicolumn{7}{|l|}{ Marital status (single as ref.) } \\
\hline Married & 0.36 & $(0.08,1.64)$ & 0.56 & $(0.18,1.72)$ & 0.97 & $(0.11,8.34)$ \\
\hline Divorced/widowed & 0.38 & $(0.08,1.96)$ & 0.91 & $(0.27,3.05)$ & 1.25 & $(0.13,11.68)$ \\
\hline \multicolumn{7}{|c|}{ Educational level (primary school or below as ref.) } \\
\hline Middle or high school & 0.49 & $(0.19,1.26)$ & 0.84 & $(0.39,1.80)$ & 1.29 & $(0.38,4.39)$ \\
\hline College or above & $0.20 * *$ & $(0.07,0.59)$ & 1.00 & $(0.46,2.19)$ & 0.98 & $(0.27,3.64)$ \\
\hline \multicolumn{7}{|c|}{ Occupational status (employed as ref.) } \\
\hline Unemployed & 0.47 & $(0.11,2.08)$ & 3.62 & $(0.79,16.57)$ & $\mathrm{N} / \mathrm{A}$ & $\mathrm{N} / \mathrm{A}$ \\
\hline Pensioner or retired & 0.45 & $(0.07,3.07)$ & 1.96 & $(0.31,12.53)$ & $\mathrm{N} / \mathrm{A}$ & $\mathrm{N} / \mathrm{A}$ \\
\hline \multicolumn{7}{|c|}{ Household income (below above as ref.) } \\
\hline Average & 0.62 & $(0.31,1.24)$ & 0.99 & $(0.61,1.60)$ & 1.12 & $(0.49,2.58)$ \\
\hline Above average & 0.43 & $(0.15,1.28)$ & 1.21 & $(0.66,2.24)$ & 1.25 & $(0.43,3.66)$ \\
\hline \multicolumn{7}{|l|}{ Health status (poor as ref.) } \\
\hline Satisfactory & 1.40 & $(0.47,4.21)$ & 1.05 & $(0.53,2.06)$ & 1.21 & $(0.40,3.66)$ \\
\hline Excellent & 0.89 & $(0.28,2.86)$ & 0.77 & $(0.38,1.56)$ & 1.09 & $(0.34,3.47)$ \\
\hline \multicolumn{7}{|c|}{ Medical condition (no chronic diseases as ref.) } \\
\hline Yes & 0.80 & $(0.41,1.56)$ & 1.29 & $(0.86,1.94)$ & 1.56 & $(0.76,3.19)$ \\
\hline
\end{tabular}

Note. $\mathrm{PB}=$ preventive behaviors; $\mathrm{PA}=$ physical activity; $\mathrm{FVC}=$ fruit and vegetable consumption; $\mathrm{N} / \mathrm{A}=$ not applicable: the statistical analysis could not be conducted due to the unbalanced data distribution; ${ }^{* *} p<0.01,{ }^{*} p<0.05$.

As presented in Table 3, multi-level binary logistic regression models were employed to examine the association of mental responses with demographic correlates and behavioral responses. In Model 1, participants who perceived satisfactory $(\mathrm{OR}=0.42,95 \% \mathrm{CI}=0.21$ to $0.84, p=0.014$ ) and excellent ( $\mathrm{OR}=0.23,95 \% \mathrm{CI}=0.11$ to $0.48, p<0.001$ ) health status were less likely to indicate significant depressive symptoms compared with those who reported bad health status. In Model 2, after controlling for the demographics, depression was found to be significantly and positively associated with both decreased FVC (OR $=2.77$, $95 \% \mathrm{CI}=1.35$ to $5.69, p=0.006)$ and non-adherence of $\mathrm{PB}(\mathrm{OR}=2.84,95 \% \mathrm{CI}=1.51$ to $5.33, p=0.001)$. The entire model of demographics and behavioral correlates showed a moderate effect size for explaining the variance in participants' depressive symptoms (Cohen's $f^{2}=0.22$ ).

For loneliness, there were no statistically significant associations between demographic correlates and loneliness ( $p=0.189$ to 0.973$)$ in Model 1. After controlling for demographics, a significantly positive associated was found between decreased PA and severe loneliness $(\mathrm{OR}=2.01,95 \% \mathrm{CI}=1.32$ to $3.05, p=0.001)$ in Model 2. The entire model of demographics and behavioral correlates showed a small effect size for explaining the variance in participants' loneliness (Cohen's $f^{2}=0.06$ ). The zero-order Spearman correlation matrix can be found in Appendix A. 
Table 3. Associations of demographics and behavioral responses with mental responses $(n=516)$.

\begin{tabular}{|c|c|c|c|c|c|c|c|c|}
\hline \multirow{3}{*}{ Variable } & \multicolumn{4}{|c|}{ Depression } & \multicolumn{4}{|c|}{ Loneliness } \\
\hline & \multicolumn{2}{|c|}{ Model 1} & \multicolumn{2}{|c|}{ Model 2} & \multicolumn{2}{|c|}{ Model 1} & \multicolumn{2}{|c|}{ Model 2} \\
\hline & OR & $95 \% \mathrm{CI}$ & OR & $95 \% \mathrm{CI}$ & OR & $95 \% \mathrm{CI}$ & OR & $95 \% \mathrm{CI}$ \\
\hline \multicolumn{9}{|c|}{ Age group (60-69 yrs. as ref.) } \\
\hline $70-79$ yrs. & 0.83 & $(0.52,1.35)$ & 0.82 & $(0.50,1.35)$ & 0.81 & $(0.52,1.26)$ & 0.81 & $(0.52,1.26)$ \\
\hline$\geq 80$ yrs. & 0.74 & $(0.32,1.75)$ & 0.64 & $(0.26,1.47)$ & 0.65 & $(0.30,1.38)$ & 0.63 & $(0.29,1.36)$ \\
\hline \multicolumn{9}{|l|}{ Gender (male as ref.) } \\
\hline Female & 0.79 & $(0.52,1.21)$ & 0.84 & $(0.54,1.29)$ & 1.18 & $(0.80,1.73)$ & 1.15 & $(0.78,1.70)$ \\
\hline \multicolumn{9}{|c|}{ Living situation (alone as ref.) } \\
\hline Not alone & 0.86 & $(0.41,1.80)$ & 1.07 & $(0.49,2.35)$ & 1.08 & $(0.53,2.20)$ & 1.00 & $(0.48,2.07)$ \\
\hline \multicolumn{9}{|l|}{ Marital status (single as ref.) } \\
\hline Married & 0.73 & $(0.22,2.51)$ & 0.87 & $(0.24,3.20)$ & 0.67 & $(0.20,2.27)$ & 0.72 & $(0.21,2.48)$ \\
\hline Divorced/widowed & 1.68 & $(0.45,6.18)$ & 1.98 & $(0.50,7.89)$ & 0.60 & $(0.17,2.19)$ & 0.59 & $(0.16,2.21)$ \\
\hline \multicolumn{9}{|c|}{ Educational level (primary school or below as ref.) } \\
\hline Middle or high school & 0.70 & $(0.32,1.52)$ & 0.75 & $(0.33,1.69)$ & 0.91 & $(0.43,1.94)$ & 0.94 & $(0.44,2.00)$ \\
\hline College or above & 0.55 & $(0.25,1.24)$ & 0.64 & $(0.27,1.50)$ & 0.81 & $(0.37,1.77)$ & 0.79 & $(0.36,1.73)$ \\
\hline \multicolumn{9}{|c|}{ Occupational status (employed as ref.) } \\
\hline Unemployed & 0.89 & $(0.27,2.97)$ & 0.84 & $(0.24,2.91)$ & 0.93 & $(0.31,2.81)$ & 0.82 & $(0.27,2.50)$ \\
\hline Pensioner or retired & 0.65 & $(0.13,3.18)$ & 0.59 & $(0.11,3.06)$ & 0.85 & $(0.20,3.69)$ & 0.84 & $(0.19,3.70)$ \\
\hline \multicolumn{9}{|c|}{ Household income (below above as ref.) } \\
\hline Average & 0.81 & $(0.50,1.33)$ & 0.83 & $(0.50,1.39)$ & 1.03 & $(0.64,1.65)$ & 1.02 & $(0.63,1.66)$ \\
\hline Above average & 0.58 & $(0.30,1.14)$ & 0.59 & $(0.29,1.17)$ & 1.10 & $(0.60,2.20)$ & 1.07 & $(0.58,1.97)$ \\
\hline \multicolumn{9}{|l|}{ Health status (poor as ref.) } \\
\hline Satisfactory & $0.42 *$ & $(0.21,0.84)$ & $0.37^{* *}$ & $(0.18,0.76)$ & 1.33 & $(0.68,2.60)$ & 1.35 & $(0.69,2.66)$ \\
\hline Excellent & $0.23^{* * *}$ & $(0.11,0.48)$ & $0.21^{* * *}$ & $(0.10,0.46)$ & 1.71 & $(0.85,3.44)$ & 1.81 & $(0.89,3.69)$ \\
\hline \multicolumn{9}{|c|}{ Medical condition (no chronic diseases as ref.) } \\
\hline Yes & 1.10 & $(0.70,1.72)$ & 1.04 & $(0.65,1.64)$ & 1.00 & $(0.66,1.50)$ & 0.97 & $(0.64,1.47)$ \\
\hline \multicolumn{9}{|l|}{ PA (same and more as ref.) } \\
\hline Decrease & $\mathrm{N} / \mathrm{A}$ & $\mathrm{N} / \mathrm{A}$ & 1.39 & $(0.90,2.15)$ & $\mathrm{N} / \mathrm{A}$ & $\mathrm{N} / \mathrm{A}$ & $2.01 * *$ & $(1.32,3.05)$ \\
\hline \multicolumn{9}{|l|}{ FVC (same and more as ref.) } \\
\hline Decrease & $\mathrm{N} / \mathrm{A}$ & $\mathrm{N} / \mathrm{A}$ & $2.77 * *$ & $(1.35,5.69)$ & $\mathrm{N} / \mathrm{A}$ & $\mathrm{N} / \mathrm{A}$ & 0.62 & $(0.31,1.23)$ \\
\hline \multicolumn{9}{|l|}{ PB (adherence as ref.) } \\
\hline Non-adherence & $\mathrm{N} / \mathrm{A}$ & $\mathrm{N} / \mathrm{A}$ & $2.84 * *$ & $(1.51,5.33)$ & $\mathrm{N} / \mathrm{A}$ & $\mathrm{N} / \mathrm{A}$ & 0.82 & $(0.45,1.52)$ \\
\hline
\end{tabular}

Note. PB = preventive behaviors; PA = physical activity; FVC = fruit and vegetable consumption; N $/ \mathrm{A}=$ not applicable; $* * *<0.001$,

** $p<0.01,{ }^{*} p<0.05$.

\section{Discussion}

This is the first online cross-sectional study to comprehensively explore the characteristics of behavioral responses $(\mathrm{PB}, \mathrm{PA}$, and $\mathrm{FVC}$ ) and mental responses (depression and loneliness) towards the COVID-19 pandemic among Chinese older adults. Nonnegligible percentages of Chinese older adults showed negative behavioral responses (i.e., non-adherence to $\mathrm{PB}$, decreased $\mathrm{PA}$ and $\mathrm{FVC}$ ) during the pandemic, while the mental responses were alarming. For older adults' behavioral responses, PB, PA, and FVC were found to differ significantly in diverse demographics. For older adults' mental responses, only depression differed significantly in demographics, while loneliness did show specific patterns. Age group, living situation, and education levels were significantly associated with PB and FVC. After controlling for demographics, there were significant associations found between behavioral responses and loneliness among Chinese older adults.

Our research findings have identified demographic differences in both behavioral and mental responses among the study sample, suggesting that future intervention development and policy making should take the participants' demographic characteristics into consideration. For the behavioral responses, despite the relevant legal penalties and mass information campaigns, we found there were still few older adults who did not comply with the recommended $\mathrm{PB}$. Consistent with other studies, the percentage of older adults non-adhering to PB was not high (Ye et al. 2020); however, there is still a need to promote the adoption of $\mathrm{PB}$ in response to the pandemic among older adults especially due to the high vulnerability and severity of this population (Singh and Singh 2020). For PA, it is 
not surprising that more than $35 \%$ of older adults decreased their weekly PA. This finding is consistent with other empirical evidence, where the decreased PA may be attributed to both governmental policy (e.g., closure of parks, gyms, or sport centers) and fear of infection while doing exercise outside (Hu et al. 2020; Qin et al. 2020; Wilczyńska et al. 2021; Schrack et al. 2020). For FVC, most older adults maintained or increased the fruit and vegetable consumption, where similar findings have been also reported in previous studies. Based on psychological theories of behavior change (e.g., social cognition theory), we conclude that the governmental efforts (e.g., increase the supply of food after the lockdown) social support, and older adults' heath knowledge and belief, may play an important role in maintaining and increasing nutritional food consumption (Anderson et al. 2007). This assumption needs to be further examined especially within the pandemic context in future research. Overall, the findings of behavioral responses highlight the need of more supportive measures to promote the adherence of PB and facilitate the adoption of healthy lifestyle behaviors during the pandemics (e.g., governmental welfare, behavior promotion campaigns, education workshops). For the mental responses, consistent with previous evidence, the situation of older adults' mental problems was alarming during the pandemic (Yang et al. 2020; Wu 2020; Wang et al. 2020). This highlights an urgent need of mental healthcare services for older adults during the COVID-19 and future pandemics (Wu 2020).

For the associations among demographics, behavioral responses, and mental responses, we found that the older adults who lived alone and had lower education levels were more likely to not comply with the $\mathrm{PB}$ in response to the pandemic, while older adults who were older were more likely to decrease the daily FVC. Consistent with previous studies, these findings emphasized the importance and necessity of caring for the social disadvantaged sample, e.g., enhancing the social and governmental support, organizing educational workshops (Shankar et al. 2010; Li et al. 2020). In line with previous studies, we found that older adults who did not adhere to PB and decreased daily FVC were more likely to show significant depressive symptoms, while those who decreased weekly PA were more likely to show severe loneliness (Wang et al. 2020; Stickley et al. 2020; Kingsbury et al. 2016; Pels and Kleinert 2016). These findings emphasize the importance of promoting positive behavioral responses (e.g., comply with PB, perform healthy lifestyles) among older adults during the pandemic, with the aim to promote their mental well-being and overall health. Our findings also demonstrate implications for the economy aspects. Particularly given the large healthcare (USD 0.62 billion) and societal costs (USD 383.02 billion) related to the COVID-19 pandemic (Jin et al. 2021), promoting such positive behavioral responses will be beneficial not only for mitigating the adverse physical and mental impacts of the pandemic towards individuals, but also for lessening the huge burden on healthcare systems in terms of hospitalization, medication, staff, and equipment for critical care costs.

Despite the implications of this study, several limitations need to be considered. First, due to the convenience sampling and the use of online questionnaire survey, the participants may vary in relation to the actual patterns of the general older adults. More empirical studies with a larger sample size using random stratified sampling are needed in the future to enhance the representativeness and external validity. Moreover, the data was obtained from a specific age group from Hubei province in China; therefore, it is unclear whether these findings could be generalized to other age groups and different cultural contexts. Furthermore, the use of self-reported scales might lead to recall bias, self-perception bias, and social desirability effects (Liu et al. 2021). Additionally, PA and FVC used one item in the study which might influence the accuracy of measuring target outcomes and applying comprehensive questionnaires to measure these variables is warranted in future studies. Finally, the causal relationship and underlying mechanisms of the associations could be identified in this study due to the use of cross-sectional design and without inclusion of some theory-based psychosocial determinants. More research on this issue is warranted. 


\section{Conclusions}

The current study investigated the characteristics of Chinese older adults' behavioral and mental responses towards the COVID-19 pandemic and examined the interrelationships among demographics, behavioral responses, and mental responses among Chinese older adults. Older adults' behavioral responses differed significantly in diverse demographics, such as age group, living situation, marital status, education levels, household income, and medical condition, while in terms of mental responses, only depressive symptoms differed significantly in several demographics, yet older adults' loneliness did not show any special characteristics. The findings revealed the importance of considering different demographics when designing interventions and making relevant policies in the fight against the pandemic. Older adults' negative mental responses were significantly associated with negative behavioral responses, suggesting the need and necessity of developing more health behavior promotion programs for mitigating the negative impacts of the pandemic and for achieving the long-term advocacy of healthy aging. Overall, our findings may add value to research and practice of promoting health among older adults during COVID-19 and future pandemics. Further studies that use a stricter scientific design with a larger sample size and objective measures that examine psychological mechanisms with inclusion of theory-based constructs are warranted in the future.

Author Contributions: Conceptualization, Y.D. and W.L.; methodology, W.L., Y.D., B.S. and C.H.; software, W.L. and M.Y.; validation, Y.D., W.L. and C.H.; formal analysis, M.Y. and W.L.; investigation, all authors; resources, all authors; data curation, Y.D., W.L. and M.Y.; writing-original draft preparation, W.L.; writing-review and editing, J.S.B.; project administration, Y.D.; funding acquisition, Y.D. All authors have read and agreed to the published version of the manuscript.

Funding: This research was funded by the Start-Up Grant and Strategic Development Fund (SDF) of Hong Kong Baptist University (HKBU). The funding organization had no role in the study design, study implementation, data collection, data analysis, manuscript preparation, or publication decision. The work is the responsibility of the authors. The APC was funded by the conference "Transnational and Transdisciplinary Lessons from the Covid-19 Pandemic", an International Symposium Organized by the Department of Government and International Studies in association, HKBU with the Department of Sport, Physical Education and Health, HKBU and the David C Lam Institute for East-West Studies.

Institutional Review Board Statement: The study was conducted according to the guidelines of the Declaration of Helsinki, and approved by the Research Ethics Committee of Hong Kong Baptist University (REC/19-20/0490).

Informed Consent Statement: Informed consent was obtained from all subjects involved in the study.

Data Availability Statement: Available from the corresponding author on reasonable request.

Acknowledgments: We would like to express our gratitude to all the contributions made by the researchers who were involved in the project.

Conflicts of Interest: The authors declare no conflict of interest. 


\section{Appendix A}

Table A1. Spearman correlation matrix of study variables.

\begin{tabular}{|c|c|c|c|c|c|c|c|c|c|c|c|c|c|}
\hline & 1 & 2 & 3 & 4 & 5 & 6 & 7 & 8 & 9 & 10 & 11 & 12 & 13 \\
\hline 1. Age & 1.000 & & & & & & & & & & & & \\
\hline 2. Gender & -0.035 & & & & & & & & & & & & \\
\hline 3. Living situation & $-0.140 * *$ & $-0.124 * *$ & & & & & & & & & & & \\
\hline 4. Marital status & $0.143 * *$ & $0.123 * *$ & -0.370 ** & & & & & & & & & & \\
\hline 5. Education level & $-0.150 * *$ & $-0.139 * *$ & 0.064 & -0.175 ** & & & & & & & & & \\
\hline 6. Occupation & $0.151 * *$ & 0.079 & -0.060 & $0.155^{* *}$ & $-0.241^{* *}$ & & & & & & & & \\
\hline 7. Household Income & 0.011 & -0.022 & $0.115^{* *}$ & $-0.133^{* *}$ & $0.295 * *$ & $-0.153^{* *}$ & & & & & & & \\
\hline 8. Health status & $-0.190 * *$ & 0.010 & 0.012 & -0.009 & 0.040 & $-0.138^{* *}$ & $0.172 * *$ & & & & & & \\
\hline 9. Medical condition & $0.170 * *$ & -0.046 & -0.022 & -0.003 & 0.052 & -0.030 & -0.063 & $-0.418^{* *}$ & & & & & \\
\hline 11. PA change & 0.076 & 0.037 & -0.027 & 0.054 & 0.029 & 0.025 & 0.021 & $-0.104 *$ & $0.100 *$ & 0.043 & & & \\
\hline 12. FVC change & $0.110 *$ & -0.013 & -0.072 & 0.061 & -0.046 & 0.065 & -0.003 & -0.052 & 0.072 & 0.032 & $0.287^{* *}$ & & \\
\hline 13. Depression & 0.038 & -0.018 & $-0.090 *$ & 0.130 ** & $-0.104 *$ & 0.049 & $-0.151^{* *}$ & $-0.212 * *$ & 0.103 * & $0.191 * *$ & $0.132 * *$ & $0.163 * *$ & \\
\hline 14. Loneliness & -0.079 & 0.045 & 0.020 & -0.036 & -0.013 & -0.027 & 0.023 & $0.095 *$ & -0.049 & -0.024 & $0.117^{* *}$ & -0.033 & -0.015 \\
\hline
\end{tabular}

Note. $\mathrm{PB}=$ preventive behaviors; PA = physical activity; FVC = fruit and vegetable consumption. ${ }^{* *} p<.01,{ }^{*} p<.05$. 


\section{References}

Amatriain-Fernández, Sandra, Eric Simón Murillo-Rodríguez, Thomas Gronwald, Sergio Machado, and Henning Budde. 2020. Benefits of physical activity and physical exercise in the time of pandemic. Psychological Trauma: Theory, Research, Practice, and Policy 12: S264. [CrossRef] [PubMed]

Anderson, Eileen S., Richard A. Winett, and Janet R. Wojcik. 2007. Self-regulation, self-efficacy, outcome expectations, and social support: Social cognitive theory and nutrition behavior. Annals of Behavioral Medicine 34: 304-12. [CrossRef] [PubMed]

Andresen, Elena M., Judith A. Malmgren, William B. Carter, and Donald L. Patrick. 1994. Screening for depression in well older adults: Evaluation of a short form of the CES-D. The American Journal of Preventive Medicine 10: 77-84. [CrossRef]

Arora, Teresa, and Ian Grey. 2020. Health behaviour changes during COVID-19 and the potential consequences: A mini-review. Journal of Health Psychology 25: 1155-63. [CrossRef]

Balkhi, Fizra, Aamna Nasir, Arhama Zehra, and Ramsha Riaz. 2020. Psychological and behavioral response to the coronavirus (COVID-19) pandemic. Cureus 12: e7923. [CrossRef]

Caputo, Eduardo L., and Felipe F. Reichert. 2020. Studies of physical activity and COVID-19 during the pandemic: A scoping review. Journal of Physical Activity and Health 17: 1275-84. [CrossRef] [PubMed]

Cheng, Cindy, Joan Barceló, Allison Spencer Hartnett, Robert Kubinec, and Luca Messerschmidt. 2020. COVID-19 government response event dataset (CoronaNet v. 1.0). Nature Human Behaviour 4: 756-68. [CrossRef]

Codagnone, Cristiano, Francesco Bogliacino, Camilo Gómez, Rafael Charris, Felipe Montealegre, Giovanni Liva, Francisco LupiáñezVillanueva, Frans Folkvord, and Giuseppe A. Veltri. 2020. Assessing concerns for the economic consequence of the COVID-19 response and mental health problems associated with economic vulnerability and negative economic shock in Italy, Spain, and the United Kingdom. PLoS ONE 15: e0240876. [CrossRef]

Center for Systems Science and Engineering (CSSE) at Johns Hopkins University, USA. 2021. Available online: https: / / gisanddata. maps.arcgis.com/apps/opsdashboard/index.html\#/bda7594740fd40299423467b48e9ecf6 (accessed on 26 September 2021).

Cunningham, Conor, Roger O'Sullivan, Paolo Caserotti, and Mark A. Tully. 2020. Consequences of physical inactivity in older adults: A systematic review of reviews and meta-analyses. The Scandinavian Journal of Medicine E Science in Sports 30: 816-27. [CrossRef]

De Jong Gierveld, Jenny, and Theo Van Tilburg. 1999. Manual of the loneliness scale 1999. Department of Social Research Methodology, Vrije Universiteit Amsterdam, Amsterdam (Updated Version 1801 02). Available online: https:/ /home.fsw.vu.nl/TG.van.Tilburg/ manual_loneliness_scale_1999.html (accessed on 26 September 2021).

Duan, Yanping, Sonia Lippke, Wei Liang, Borui Shang, Wagner Petra, Julien Steven Baker, Jiali He, and Franziska Marie Keller. 2021. Association of social-cognitive factors with individual preventive behaviors of Covid-19 among a mixed-sample of older adults from China and Germany. Res-Square. Available online: https://www.researchsquare.com/article/rs-503762/v1 (accessed on 26 September 2021). [CrossRef]

Dwyer, Michael John, Margherita Pasini, Stefano De Dominicis, and Elda Righi. 2020. Physical activity: Benefits and challenges during the COVID-19 pandemic. The Scandinavian Journal of Medicine E Science in Sports 30: 1291. [CrossRef]

Gehlich, Kerstin H., Johannes Beller, Bernhard Lange-Asschenfeldt, Wolfgang Köcher, Martina C. Meinke, and Jürgen Lademann. 2019. Fruit and vegetable consumption is associated with improved mental and cognitive health in older adults from non-Western developing countries. Public Health Nutrition 22: 689-96. [CrossRef] [PubMed]

$\mathrm{Hu}$, Zhao, Xuhui Lin, Atipatsa Chiwanda Kaminga, and Huilan Xu. 2020. Impact of the COVID-19 epidemic on lifestyle behaviors and their association with subjective well-being among the general population in mainland China: Cross-sectional study. The Journal of Medical Internet Research 22: e21176. [CrossRef]

$\mathrm{Hu}$, Xinyi, Antoine Flahault, Alexander Temerev, and Liudmila Rozanova. 2021. The Progression of COVID-19 and the Government Response in China. International Journal of Environmental Research and Public Health 18: 3002. [CrossRef] [PubMed]

Jin, Huajie, Haiyin Wang, Xiao Li, Weiwei Zheng, Shanke Ye, Sheng Zhang, Jiahui Zhou, and Mark Pennington. 2021. Economic burden of COVID-19, China, January-March, 2020: A cost-of-illness study. Bulletin of the World Health Organization 99: 112. [CrossRef]

Khan, Kiran Shafiq, Mohammed A. Mamun, Mark D. Griffiths, and Irfan Ullah. 2020. The mental health impact of the COVID-19 pandemic across different cohorts. International Journal of Mental Health and Addiction 9: 1-7. [CrossRef]

Kingsbury, Mila, Gabrielle Dupuis, Felice Jacka, Marie-Hélène Roy-Gagnon, Seanna E. McMartin, and Ian Colman. 2016. Associations between fruit and vegetable consumption and depressive symptoms: Evidence from a national Canadian longitudinal survey. Journal of Epidemiology and Community Health 70: 155-61. [CrossRef] [PubMed]

Leung, Grace Tak Yu, Jenny de Jong Gierveld, and Linda Chiu Wa Lam. 2008. Validation of the Chinese translation of the 6-item De Jong Gierveld Loneliness Scale in elderly Chinese. International Psychogeriatrics 20: 1262-72. [CrossRef]

Li, Xiaojing, and Qinliang Liu. 2020. Social media use, eHealth literacy, disease knowledge, and preventive behaviors in the COVID-19 pandemic: Cross-sectional study on Chinese netizens. Journal of Medical Internet Research 22: e19684. [CrossRef]

Li, Siyue, Bo Feng, Wang Liao, and Wenjing Pan. 2020. Internet use, risk awareness, and demographic characteristics associated with engagement in preventive behaviors and testing: Cross-sectional survey on COVID-19 in the United States. The Journal of Medical Internet Research 22: e19782. [CrossRef] [PubMed] 
Liang, Wei, Yan Ping Duan, Bo Rui Shang, Yan Ping Wang, Chun Hu, and Sonia Lippke. 2019. A web-based lifestyle intervention program for Chinese college students: Study protocol and baseline characteristics of a randomized placebo-controlled trial. BMC Public Health 19: 1. [CrossRef]

Liang, Wei, Yanping Duan, Borui Shang, Chun Hu, Julien Steven Baker, Zhihua Lin, Jiali He, and Yanping Wang. 2021. Precautionary behavior and depression in older adults during the COVID-19 pandemic: An online cross-sectional study in Hubei, China. International Journal of Environmental Research and Public Health 18: 1853. [CrossRef]

Litton, Michelle M., and Alyssa W. Beavers. 2020. The Relationship between Food Security Status and Fruit and Vegetable Intake during the COVID-19 Pandemic. Nutrients 13: 712. [CrossRef] [PubMed]

Liu, Hua-Xuan, Bik-Chu Chow, Wei Liang, Holger Hassel, and YaJun Wendy Huang. 2021. Measuring a broad spectrum of eHealth skills in the Web 3.0 context using an eHealth Literacy Scale: Development and validation study. The Journal of Medical Internet Research 23: e31627. [CrossRef]

López-Bueno, Rubén, Guillermo F. López-Sánchez, José A. Casajús, Joaquín Calatayud, Alejandro Gil-Salmerón, Igor Grabovac, Mark A. Tully, and Lee Smith. 2020. Health-related behaviors among school-aged children and adolescents during the Spanish Covid-19 confinement. Frontiers in Pediatrics 8: 573. [CrossRef] [PubMed]

National Health Commission of China. 2021. Update on the New Coronavirus Cases. Available online: http://health.people.com.cn/ GB/26466/431463/431576/index.html (accessed on 26 September 2021).

Pels, Fabian, and Jens Kleinert. 2016. Loneliness and physical activity: A systematic review. International Review of Sport and Exercise Psychology 9: 231-60. [CrossRef]

Pinquart, Martin. 2001. Correlates of subjective health in older adults: A meta-analysis. Psychology and Aging 16: 414. [CrossRef] [PubMed]

Probst, Tahira M., Hyun Jung Lee, and Andrea Bazzoli. 2020. Economic stressors and the enactment of CDC-recommended COVID-19 prevention behaviors: The impact of state-level context. The Journal of Applied Psychology 105: 1397-407. [CrossRef]

Puspitasari, Irma Melyani, Lutfiah Yusuf, Rano K. Sinuraya, Rizky Abdulah, and Hiroshi Koyama. 2020. Knowledge, attitude, and practice during the COVID-19 pandemic: A review. The Journal of Multidisciplinary Healthcare 13: 727. [CrossRef]

Qin, Fei, Yiqing Song, George P. Nassis, Lina Zhao, Yanan Dong, Cuicui Zhao, Yiwei Feng, and Jiexiu Zhao. 2020. Physical activity, screen time, and emotional well-being during the 2019 novel coronavirus outbreak in China. International Journal of Environmental Research and Public Health 17: 5170. [CrossRef]

Rankin, Sally H., Michael E. Galbraith, and Sharon Johnson. 1993. Reliability and validity data for a Chinese translation of the Center for Epidemiological Studies-Depression. Psychological Reports 73: 1291-98. [CrossRef]

Schrack, Jennifer A., Amal A. Wanigatunga, and Stephen P. Juraschek. 2020. After the COVID-19 pandemic: The next wave of health challenges for older adults. The Journals of Gerontology 75: e121-2. [CrossRef] [PubMed]

Selya, Arielle S., Jennifer S. Rose, Lisa C. Dierker, Donald Hedeker, and Robin J. Mermelstein. 2012. A practical guide to calculating Cohen's f2, a measure of local effect size, from PROC MIXED. Frontiers in Psychology 3: 111. [CrossRef]

Shahid, Zainab, Ricci Kalayanamitra, Brendan McClafferty, Douglas Kepko, Devyani Ramgobin, Ravi Patel, Chander Shekher Aggarwal, Ramarao Vunnam, Nitasa Sahu, Dhirisha Bhatt, and et al. 2020. COVID-19 and older adults: What we know. Journal of the American Geriatrics Society 68: 926-29. [CrossRef]

Shankar, Aparna, Anne McMunn, and Andrew Steptoe. 2010. Health-related behaviors in older adults: Relationships with socioeconomic status. The American Journal of Preventive Medicine 38: 39-46. [CrossRef]

Singh, Jaspreet, and Jagandeep Singh. 2020. COVID-19 and its impact on society. Electronic Research Journal of Social Sciences and Humanities 2. Available online: https:/ / ssrn.com/abstract=3567837 (accessed on 26 September 2021).

Stickley, Andrew, Tetsuya Matsubayashi, Hajime Sueki, and Michiko Ueda. 2020. COVID-19 preventive behaviours among people with anxiety and depressive symptoms: Findings from Japan. Public Health 189: 91-3. [CrossRef]

Usher, Kim, Debra Jackson, Joanne Durkin, Naomi Gyamfi, and Navjot Bhullar. 2020. Pandemic-related behaviours and psychological outcomes; A rapid literature review to explain COVID-19 behaviours. International Journal of Mental Health Nursing 29: 1018-34. [CrossRef]

Vahia, Ipsit V., Dilip V. Jeste, and Charles F. Reynolds. 2020. Older adults and the mental health effects of COVID-19. JAMA 324: 2253-4. [CrossRef]

Wang, Cuiyan, Riyu Pan, Xiaoyang Wan, Yilin Tan, Linkang Xu, Cyrus S. Ho, and Roger C. Ho. 2020. Immediate psychological responses and associated factors during the initial stage of the 2019 coronavirus disease (COVID-19) epidemic among the general population in China. International Journal of Environmental Research and Public Health 17: 1729. [CrossRef]

Wang, Cuiyan, Riyu Pan, Xiaoyang Wan, Yilin Tan, Linkang Xu, Roger S. McIntyre, Faith N. Choo, B. Tran, R. Ho, Vijay K. Sharma, and et al. 2020. A longitudinal study on the mental health of general population during the COVID-19 epidemic in China. Brain, Behavior, and Immunity 87: 40-48. [CrossRef] [PubMed]

Weaver, Raven H., Alexandra Jackson, Jane Lanigan, Thomas G. Power, Alana Anderson, Anne E. Cox, Linda Eddy, Louise Parker, Yoshie Sano, and Elizabeth Weybright. 2021. Health Behaviors at the Onset of the COVID-19 Pandemic. The American Journal of Health Behavior 45: 44-61. [CrossRef] [PubMed]

World Health Organization. 2020. Coronavirus Disease (COVID-19) Pandemic. Available online: https://www.who.int/emergencies/ diseases / novel-coronavirus-2019 (accessed on 15 October 2020). 
WHO. 2021a. WHO Coronavirus Disease (COVID-19) Dashboard. Available online: https://covid19.who.int/ (accessed on 26 September 2021).

WHO. 2021b. World Health Organization. Coronavirus Disease (COVID-19) Advice for the Public. Available online: https://www. who.int/emergencies/diseases/novel-coronavirus-2019/advice-for-public (accessed on 30 August 2021).

Wilczyńska, Dominika, Jianye Li, Yin Yang, Hongying Fan, Taofeng Liu, and Mariusz Lipowski. 2021. Fear of COVID-19 changes the motivation for physical activity participation: Polish-Chinese comparisons. Health Psychology Report 2: 138-48. Available online: https: / / czasopisma.bg.ug.edu.pl/index.php/HPR/article/view/5754 (accessed on 26 September 2021).

$\mathrm{Wu}$, Bei. 2020. Social isolation and loneliness among older adults in the context of COVID-19: A global challenge. Global Health Res and Policy 5: 1-3. [CrossRef] [PubMed]

Yahia, Elhadi M., María Elena Maldonado Celis, and Mette Svendsen. 2017. The contribution of fruit and vegetable consumption to human health. In Fruit and vegetable Phytochemicals. Edited by E. M. Yahia. Hoboken: John Wiley \& Sons, vol. 29 , pp. 3-52.

Yang, Yuan, Wen Li, Qinge Zhang, Ling Zhang, Teris Cheung, and Yu-Tao Xiang. 2020. Mental health services for older adults in China during the COVID-19 outbreak. The Lancet Psychiatry 7: e19. [CrossRef]

Ye, Yisheng, Ruoxi Wang, Da Feng, Ruijun Wu, Zhifei Li, Chengxu Long, Zhanchun Feng, and Shangfeng Tang. 2020. The recommended and excessive preventive behaviors during the COVID-19 pandemic: A community-based online survey in China. International Journal of Environmental Research and Public Health 17: 6953. [CrossRef] 